\title{
Electrochemical investigation into the effect of nano-titania on the protective properties of epoxy coatings on mild steel in natural seawater
}

\begin{abstract}
The effect of introducing nano-tinania $\left(\mathrm{TiO}_{2}\right)$ particles to the epoxy coatings on mild steel in natural seawater was analyzed using Scanning Electrochemical Microscopy (SECM) and Electrochemical Impedance Spectroscopy (EIS). Line profile and topographic image analysis were measured by applying $-0.70 \mathrm{~V}$ and $+0.60 \mathrm{~V}$ as the tip potential for the cathodic and anodic reactions, respectively. The tip current at $-0.70 \mathrm{~V}$ for the epoxy coated sample with $\mathrm{TiO}_{2}$ nanoparticles decreased rapidly due to cathodic reduction of dissolved oxygen. The EIS measurements were conducted in natural seawater after wet and dry cyclic corrosion test. The EIS measured the film resistance $\left(\mathrm{R}_{\mathrm{f}}\right)$ and charge transfer resistance $\left(\mathrm{R}_{\mathrm{ct}}\right)$ values which were increased by the addition of $\mathrm{TiO}_{2}$ nanoparticles in the epoxy coating. SEM/EDX and FIB-TEM analysis showed that complex oxides of titania were enriched in corrosion products at the scratched area of the coated steel and confirmed the presence of the nanoscale oxide layers of titania in the rust of the steel. The formation of complex oxides of titania had a beneficial effect on the corrosion resistance of coated steel.
\end{abstract}

Volume 2 Issue I - 2017

\author{
X Joseph Raj, ${ }^{1,2} T$ Nishimura ${ }^{2}$ \\ 'Department of Chemistry,Veltech Dr.RR \& Dr.SR University, \\ India \\ ${ }^{2}$ Materials Recycling Design Group, National Institute for \\ Materials Science, Japa
}

\begin{abstract}
Correspondence: X Joseph Raj, Department of Chemistry,
\end{abstract} Veltech Dr.RR \& Dr.SR University, India,

Email drjosephrajxavier@gmail.com

Received: January 29, 2017 | Published: February 2I, 2017

Keywords: corrosion, epoxy coating, $\mathrm{TiO}_{2}$, nanoparticle, EIS, SECM

\section{Introduction}

In Oil \& Gas industry, the total loss due to Corrosion and Erosion (Wear) is calculated approx US $\$ 500$ Billion. The protection problem arises from rain rapidly saturating the outer skin, particularly through mortar joints, and wetting the exposed steelwork Figure 1. The design should ensure adequate drainage the steelwork. Various parts of connections need to be protected by a coating system including high performance paint systems. Many factors contribute to the complexity of designing efficient pipeline coating formulations; climate, properties of the substrate traveling through the pipeline, product flammability and rate of flow to name a few. In addition it must be taken into consideration if the pipeline is laid underwater, underground or above ground and the coating must be formulated to provide long term internal and external durability, the coating must be formulated with some basic tenets in mind. Epoxy coatings for oil and gas applications offer excellent resistance to high temperatures, chemicals and corrosion. Cathodic protection and polymeric coatings are usually employed to protect metallic constructions against the corrosion, but isolating the metal from corrosive agents is still the most conventional method to prevent corrosion. ${ }^{1-3}$ In this regard, polymeric coatings can provide protection either by a barrier action from the layer or from active corrosion inhibition supplied by pigments in the coating, which give protection to the underlying substrate. ${ }^{4}$ However all polymeric coatings are permeable to corrosive species such as oxygen, water and ions to some extent..$^{5-8}$ Water molecules at the metal/coating interface may reduce the coating adhesion, thus favoring corrosion of the metal underneath the film.

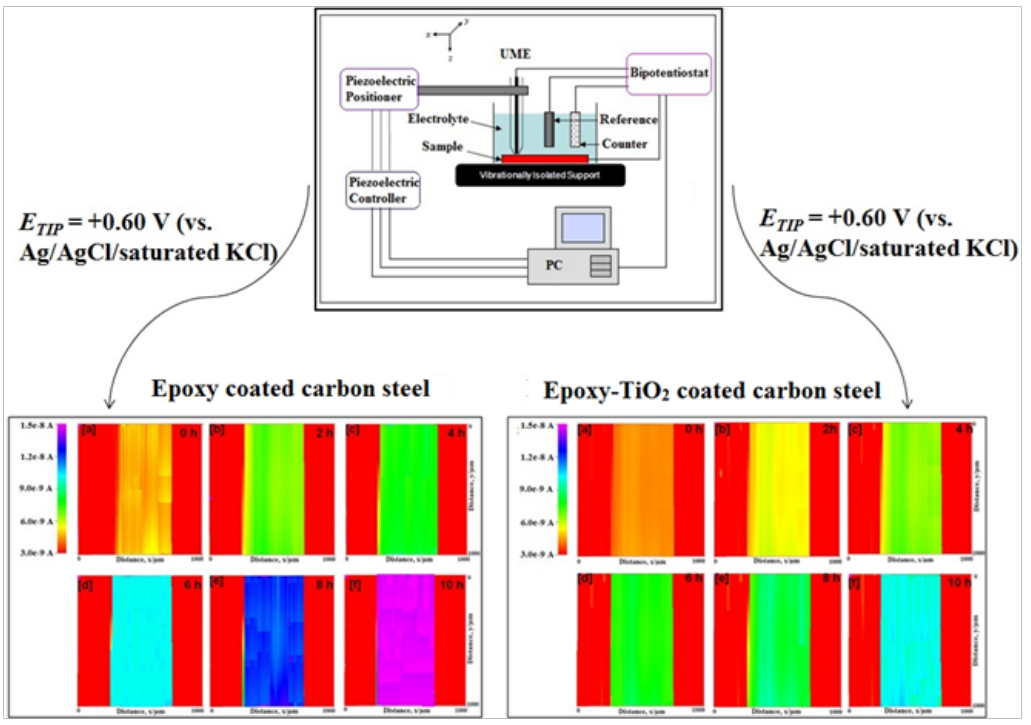

Figure I Graphical Abstract. 
Nanoparticles, owing to high specific surface area and small particle size, can enhance the corrosion resistance of the organic coatings by increasing the electrolyte pathways length. Inclusion of metal nanoparticles to the organic coating provides cathodic protection to the underlying substrate. They also provide barrier and passive protection by generating oxides at a later stage. The importance of nanomaterials compared to conventional micro sized pigments is mainly due to their small size and large specific surface area. The decrease in size of the particles causes mechanical properties enhancement of the coating. There are a large number of reports indicating that the anticorrosion properties of the polyurethane coatings can be markedly improved in the presence of nanoparticles. ${ }^{9-16}$ Titanium oxide is highly corrosion resistant and provides a barrier protection which is stable over a wide $\mathrm{pH}$ range. It is not classified as dangerous for human health and for environment. This has shown interest in using titanium oxide in organic coatings in the corrosion protection of steel. SECM has been introduced to evaluate the localized corrosion process, since it provides electrochemical activity and topographic information about the surface reactions at the micrometer scale in aqueous environments. ${ }^{17-21}$ The application of SECM has facilitated

Table I Chemical composition of Mild steel specimen. experiments on the solid/liquid interface because of its high spatial resolution and electrochemical sensitivity.

In this study, SECM was used primarily to evaluate the effect of $\mathrm{TiO}_{2}$ nanoparticles on the corrosion protection performance of an epoxy coating over mild steel in natural seawater. The tip current was detected during the corrosion of the sample at open circuit potential to evaluate the suppressing effect of the coating on the corrosion around a defect area. Additionally, electrochemical behavior of coated steel without and with $\mathrm{TiO}_{2}$ nanoparticles was investigated by the electrochemical impedance spectroscopy (EIS).

\section{Experimental procedure}

\section{Preparation of the sample}

The chemical composition of the JIS-SM CS specimen in mass \% is given in Table 1 . The steel specimens were abraded mechanically with different grades of silicon carbide papers (400-1200) and washed with double distilled water. Further the samples were degreased with acetone using ultrasonicator and thoroughly washed with double distilled water and dried in air

\begin{tabular}{lllllllllll}
\hline Sample & \multicolumn{2}{l}{ Elements (mass \%) } & & & & & & & \\
\cline { 2 - 10 } & $\mathbf{C}$ & Si & Mn & P & S & Al & N & O & Fe \\
\hline Mild Steel & 0.1 & 0.4 & 0.6 & 0.02 & 0.002 & 0.04 & 0.002 & 0.002 & Bal. \\
\hline
\end{tabular}

\section{Preparation of coatings}

Epoxy resin based on diglycidal ether of bis-phenol-A was used. It is a fast drying type and the curing agent was based on aliphatic amines. The mass ratio of the epoxy resin to the curing agent was 2:1. The sample was washed with distilled water and acetone before the application of coating. Using a wire-wound draw down bar, no. 18 from RDS specialties, epoxy was coated at a constant speed and then kept at room temperature for $24 \mathrm{~h}$. A uniform coating of thickness about $40 \mu \mathrm{m}$ was achieved. Commercially available $\mathrm{TiO}_{2}$ nanoparticle, obtained from Tokyo Chemical Industry Co. Ltd, sizes ranging from 50 to $100 \mathrm{~nm}$ were used. $\mathrm{The}^{\mathrm{TiO}} \mathrm{O}_{2}$ nanoparticles were added to the epoxy resin to produce a 10 mass percentage of $\mathrm{TiO}_{2}$ in the mixture. The sample was coated with the mixture by the same procedure. Artificial scratches with an approximate diameter of $100-150 \mu \mathrm{m}$ were produced in the coated samples. The electrolyte used was the natural seawater collected in a sterilized brown flask at Marina beach on the southern coast of Chennai, India.

\section{Scanning electrochemical spectroscopy measurements}

(SECM)

SECM was conducted over a scratched surface area of coated steel as a function of immersion time. The schematic representation of SECM experimental set up is shown in Figure 2. All the experiments were conducted at room temperature in a naturally aerated cell containing natural seawater. As reduction of oxygen is dominant for the cathodic process in corrosion, change in the concentration of dissolved oxygen due to corrosion reactions was the primary factor. SECM was performed in order to measure the concentration of oxygen in the scratched area of the coated sample as a function of time. Oxygen could be monitored at the tip of the SECM by setting the potential of the tip at $-0.70 \mathrm{~V}$ vs. the $\mathrm{Ag} / \mathrm{AgCl} /$ saturated $\mathrm{KCl}$ reference electrode. Then, the diffusion limited current of oxygen at the tip was able to be determined at this potential. The main anodic reaction for corrosion of iron in natural seawater is dissolution of iron. By setting the tip potential at $+0.60 \mathrm{~V}$ vs. $\mathrm{Ag} / \mathrm{AgCl}, \mathrm{Fe}^{2+}$ ions dissolved in the solution can be detected through their oxidation to $\mathrm{Fe}^{3+}$ at the tip. Since no $\mathrm{Fe}^{2+}$ was originally present in the test solution, it can only be originated from corrosion processes at the steel inside the scratch. In this way, soluble $\mathrm{Fe}^{2+}$ ions would diffuse away from the scratch and would be eventually detected at the tip through oxidation.

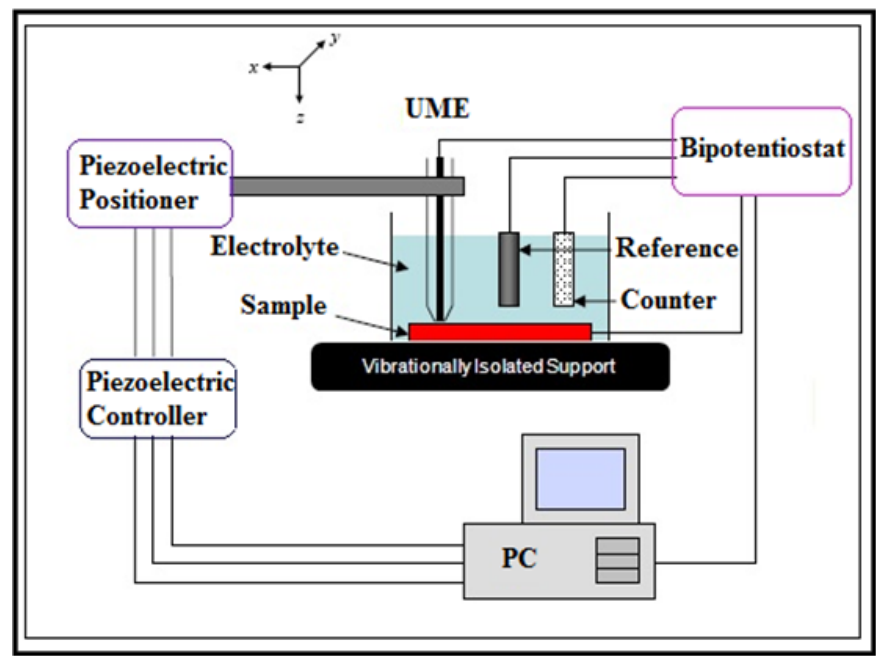

Figure 2 Schematic representation of SECM experimental set up.

In this study, SECM was conducted in natural seawater to estimate the corrosion performance of the epoxy- $\mathrm{TiO}_{2}$ coated mild steel. Platinum microelectrodes with a diameter of $10 \mu \mathrm{m}$ were employed as SECM tips. The movement of the tip was controlled in the $\mathrm{x}, \mathrm{y}$ and $\mathrm{z}$ directions using optically encoded inchworm piezo motors. The 
Pt tip was scanned at a constant height above the sample while all experiments were performed. A bipotentiostat designed for SECM was used to control the potentials of the sample and tip separately. A video microscope mounted above the cell was used to aid in positioning the microelectrode over the sample. All measurements were performed using an $\mathrm{Ag} / \mathrm{AgCl}$ reference electrode and a $\mathrm{Pt}$ wire as a counter electrode. The coated sample was mounted horizontally at the bottom of a micro flat cell. The sample of coated steel was examined at the OCP in all SECM experiments. A line scan was observed across the scratched area in the coated sample at a scan rate of $20 \mu \mathrm{m} \mathrm{s}^{-1}$ in the $x$ direction. SECM maps were obtained on the coated steel in order to detect the continuous change in corrosion at a constant height of $20 \mu \mathrm{m}$. Detailed experimental conditions for SECM are shown in Table 2.

Table 2 Experimental conditions for SECM

\begin{tabular}{|c|c|c|c|c|c|c|c|}
\hline Mode & $\begin{array}{l}\text { Redox } \\
\text { couple }\end{array}$ & $\begin{array}{l}\text { Potential,VVs. } \\
\text { Ag/Agcl (V) }\end{array}$ & $\begin{array}{l}\text { Distance bet. sample } \\
\text { \& UME (Mm) }\end{array}$ & $\begin{array}{l}\text { Scan } \\
\text { rate } \\
\left(\mu \mathrm{ms}-^{-}\right)\end{array}$ & $\begin{array}{l}\text { Reference } \\
\text { electrode }\end{array}$ & $\begin{array}{l}\text { Counter } \\
\text { electrode }\end{array}$ & Working electrode \\
\hline $\begin{array}{l}\text { Redox } \\
\text { competition }\end{array}$ & $\mathrm{O}_{2} / \mathrm{OH}-$ & -0.7 & 20 & 20 & $\mathrm{Ag} / \mathrm{AgCl}$ & $\begin{array}{l}\text { Platinum } \\
\text { wire }\end{array}$ & $\begin{array}{l}\text { Scratched Epoxy/Epoxy- } \\
\mathrm{TiO}_{2} \text { coated steel }\end{array}$ \\
\hline $\begin{array}{l}\text { Redox } \\
\text { competition }\end{array}$ & $\mathrm{Fe}^{2}+/ \mathrm{Fe}^{3}+$ & 0.6 & 20 & 20 & $\mathrm{Ag} / \mathrm{AgCl}$ & $\begin{array}{l}\text { Platinum } \\
\text { wire }\end{array}$ & $\begin{array}{l}\text { Scratched Epoxy/Epoxy- } \\
\mathrm{TiO}_{2} \text { coated steel }\end{array}$ \\
\hline
\end{tabular}

\section{Electrochemical measurement \\ impedance \\ spectroscopy}

A wet/dry cyclic test was conducted under the condition (12 $\mathrm{h}$ immersion in natural seawater and $12 \mathrm{~h}$ in the dry) for 15 days. EIS measurements were taken periodically in natural seawater for electrochemical characterization. The EIS was performed in a conventional three-electrode cell, using coated steel as the working electrode and a saturated calomel electrode (SCE) as the reference electrode. A frequency response analyzer was used for EIS measurements with amplitude of $10 \mathrm{mV}$ over a frequency range of 40 $\mathrm{kHz}$ to $1 \mathrm{mHz}$. All measurements were carried out at the open circuit potential at room temperature $\left(25^{\circ} \mathrm{C}\right)$. The EIS experimental data were analyzed using curve fittings.

\section{Surface characterization}

The surface state of the corrosion product on the coated steel was observed by FE-SEM (Field Emission Scanning Electron Microscope) and FIB-TEM (Focused Ion Beam-Transmission Electron Microscope, JEM-2100F) analysis. After the cyclic corrosion test, the coated steel was cast in resin and polished using emery paper, followed by diamond paste. Carbon was then evaporated on the sample in order to compensate for charging effects. A cross section of the rusted steel was examined using FE-SEM at an acceleration voltage of $20 \mathrm{kV}$ and irradiation current of $10 \mu \mathrm{A}$. The concentrations of $\mathrm{Fe}$ and $\mathrm{TiO}_{2}$ in the rust were measured by EDX (Energy Dispersive $\mathrm{X}$-Ray Spectroscope). TEM observation was performed with EDX analysis. The rust was cut from the inner rust by FIB, and line profile analysis was carried out in order to identify the concentrations of Fe and $\mathrm{TiO}_{2}$ in the rust.

\section{Results and discussion}

\section{Scanning electrochemical microscopy (SECM) analysis}

SECM images for the epoxy coated mild steels without and with nano-titania particles in natural seawater with scratches at the tip potential at $+0.60 \mathrm{~V}$ (vs. $\mathrm{Ag} / \mathrm{AgCl} /$ saturated $\mathrm{KCl}$ ) are depicted in Figure 3, Figure 4 respectively. The variation in color in the SECM images represents the local anodic and cathodic area in the scratched sample. The current measured at the scratch is significantly higher than that of other places. The tip current at the scratch of the epoxy coated mild steel increases with increase in test time from $4.7 \mathrm{nA}$ (orange) to $14.8 \mathrm{nA}$ (pink). This shows that dissolution of $\mathrm{Fe}^{2+}$ increases with test time. The electrochemical behavior of epoxy- $\mathrm{TiO}_{2}$ coated mild steel is same as that of the mild steel. However, the tip current at the scratch increases very slowly as compared with the epoxy coated mild steel from $4.2 \mathrm{nA}$ (orange) to $9.6 \mathrm{nA}$ (cyan). Thus, the dissolution of $\mathrm{Fe}^{2+}$ at the scratch is reduced in epoxy- $\mathrm{TiO}_{2}$ coated mild steel as compared with epoxy coated mild steel.

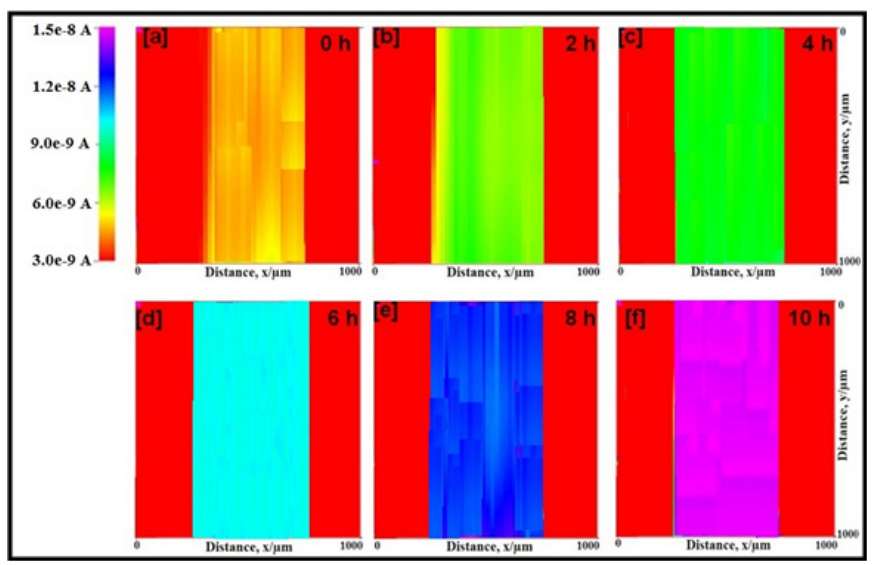

Figure 3 SECM topographic images of scratched epoxy coated mild steel in natural seawater in different hours at the tip potential of $+0.60 \mathrm{Vvs} . \mathrm{Ag} / \mathrm{AgCl} /$ $\mathrm{KCl}$ reference electrode.

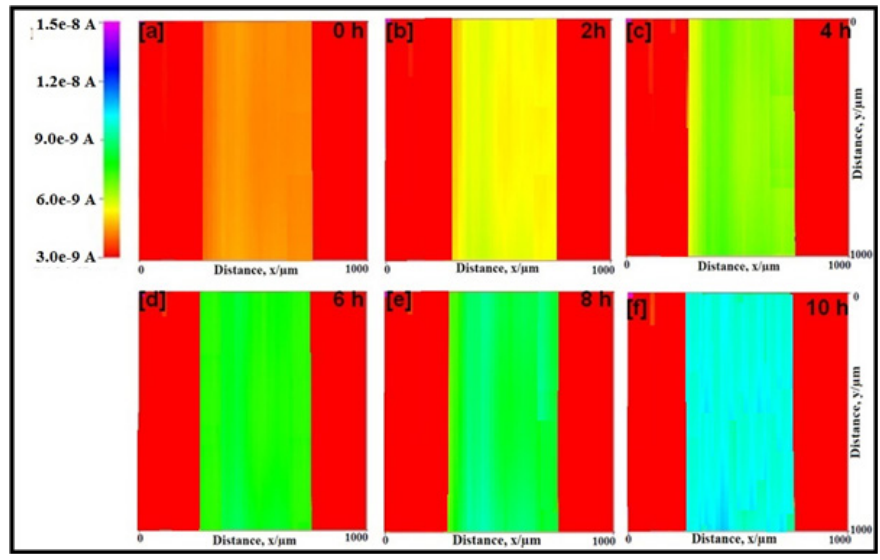

Figure $4 \mathrm{SECM}$ topographic images of scratched epoxy- $\mathrm{TiO}_{2}$ coated mild steel in natural seawater in different hours at the tip potential of $+0.60 \mathrm{~V}$ vs. $\mathrm{Ag} /$ $\mathrm{AgCl} / \mathrm{KCl}$ reference electrode. 
SECM images of epoxy and epoxy- $\mathrm{TiO}_{2}$ coated mild steel in natural seawater for different time at $-0.70 \mathrm{~V}$ are depicted in Figure 5 , Figure 6 respectively. The tip current in epoxy coated mild steel decreases with increasing test time at the scratch from $4.7 \mathrm{nA}$ to 3.1 $\mathrm{nA}$. This is shown by an increase in the red color. The intense red color near the scratched area implies that the dissolved oxygen current is very less where it is consumed by the iron from the scratched area. It shows high current for dissolved oxygen in other areas where the surface is covered with the resin. Therefore, the increase in the red color is due to a increase in the cathodic reaction at the scratch. However, in the case of epoxy- $\mathrm{TiO}_{2}$ coated mild steel, the tip current measured at the scratch is significantly smaller $(2.8 \mathrm{nA})$ than that over the coated surface $(7.9 \mathrm{nA})$. This behavior shows that the consumption of oxygen occurs at the scratch. As anodic dissolution of $\mathrm{Fe}^{2+}$ occurs, concentration of oxygen is decreased by the consumption as cathodic reaction at the scratch. It is evident from the measurement that the presence of $\mathrm{TiO}_{2}$ particles in the epoxy coating reduces the dissolution of iron from the metal surface by covering the surface by forming complexes. The formation of complexes on the metal surface provides additional barrier protection to the surface apart from the film resistance.

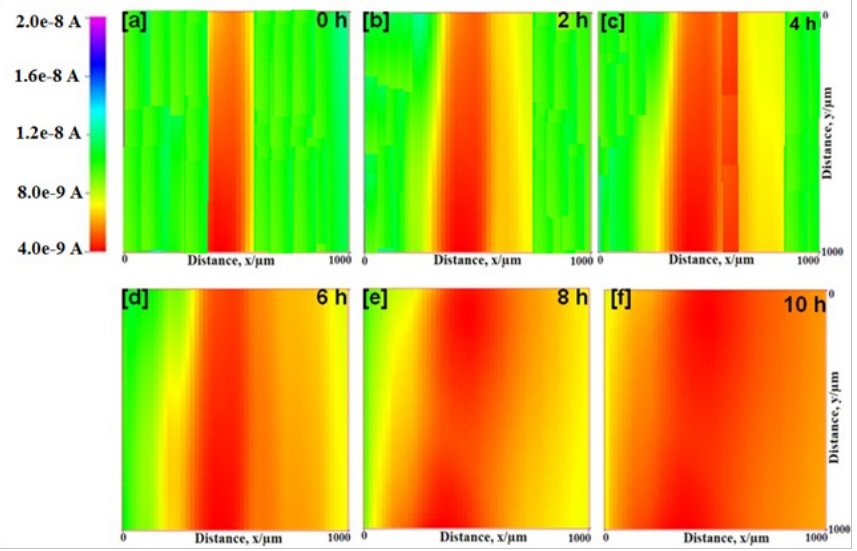

Figure 5 SECM topographic images of scratched epoxy coated mild steel in natural seawater in different time at the tip potential of $-0.70 \mathrm{~V}$ vs. $\mathrm{Ag} / \mathrm{AgCl} /$ $\mathrm{KCl}$ reference electrode.

Figure 7, Figure 8 show the SECM line scan of the tip current near the scratches on the epoxy and epoxy- $\mathrm{TiO}_{2}$ coated mild steels respectively when the tip potential was $+0.60 \mathrm{~V}$ vs. $\mathrm{Ag} / \mathrm{AgCl} /$ saturated $\mathrm{KCl}$ and $-0.70 \mathrm{~V}$ vs. $\mathrm{Ag} / \mathrm{AgCl} /$ saturated $\mathrm{KCl}$ Figure $7 \mathrm{~b}$, Figure $8 \mathrm{~b}$ respectively. The tip was moved over the scratched area (S) and unscratched area (R) during the scan as shown in Figure 7, Figure 8. It can be seen form Figure 7a, Figure 8a that the tip current at $+0.60 \mathrm{~V}$ is very high at point $\mathrm{S}$ and shows a decrease towards point $\mathrm{R}$ from the initial test time. This behavior is due to the dissolution of $\mathrm{Fe}^{2+}$ at the scratch (S). Moreover, the tip current at point $\mathrm{S}$ was smaller in the epoxy- $\mathrm{TiO}_{2}$ coated mild steel than in the epoxy coated mild steel. It suggests that the dissolution of $\mathrm{Fe}^{2+}$ is suppressed at the scratch on the epoxy- $\mathrm{TiO}_{2}$ coated steel due to the formation of the corrosion products of $\mathrm{TiO}_{2}$ complexes present in the scratch. It is seen from Figure $7 \mathrm{~b} \& 7 \mathrm{~b}$ that the tip current at $-0.70 \mathrm{~V}$ (vs. $\mathrm{Ag} / \mathrm{AgCl} /$ saturated $\mathrm{KCl}$ ) around point $\mathrm{R}$ is very high and shows a decrease in the tip current toward point $\mathrm{S}$. This behavior is due to the consumption of oxygen by the cathodic reaction at the scratch, where anodic dissolution of $\mathrm{Fe}^{2+}$ occurs. However, the diffusion current of oxygen from the bulk solution to the scratched surface is too small that the cathodic current for the epoxy coated mild steel as well as epoxy- $\mathrm{TiO}_{2}$ coated mild steel was found to be more or less same. This is due to the result of higher residual current and very small value of tip current. From this analysis, it was concluded that the rate of corrosion of the epoxy coated mild steel is much higher than that of the epoxy- $\mathrm{TiO}_{2}$ coated mild steel. These results are in good agreement with the SECM imaging results.

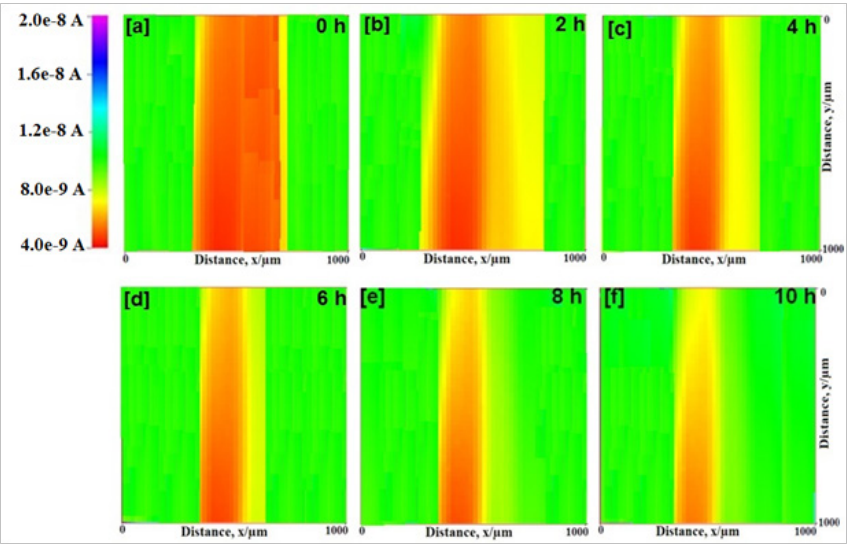

Figure 6 SECM topographic images of scratched epoxy- $\mathrm{TiO}_{2}$ coated mild steel in natural seawater in different time at the tip potential of $-0.70 \mathrm{~V} v \mathrm{v}$. Ag/ $\mathrm{AgCl} / \mathrm{KCl}$ reference electrode.
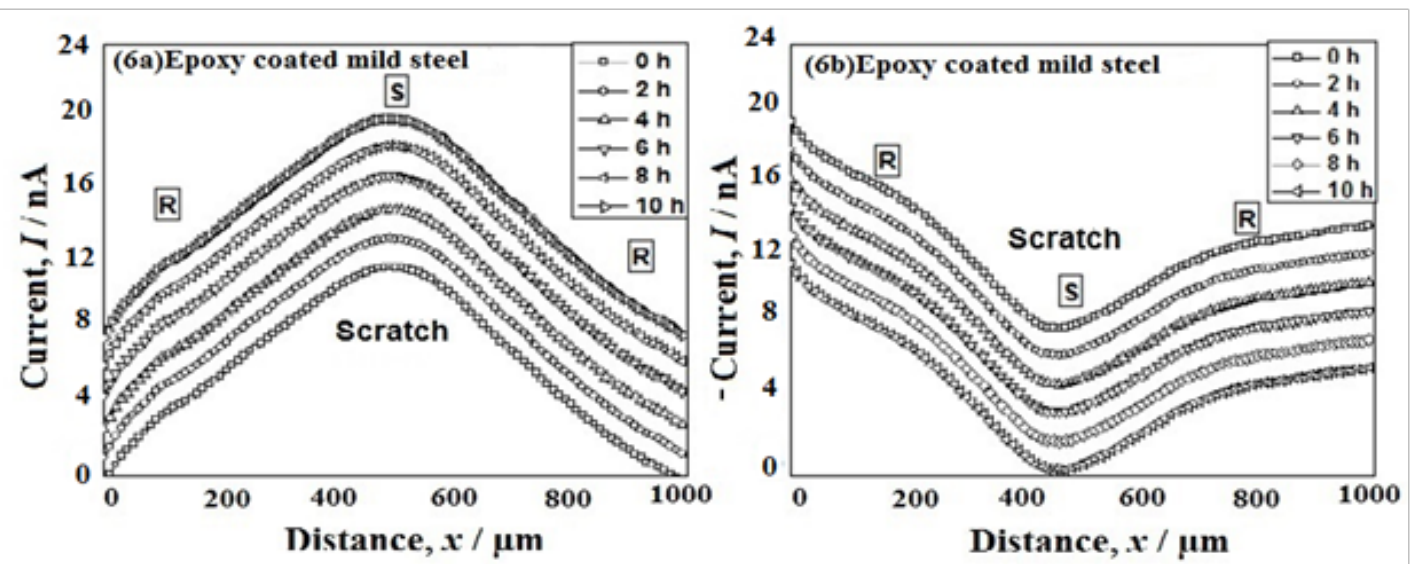

Figure $7 \mathrm{SECM}$ lines scan near the scratch of coated mild steel (Fig. $7 \mathrm{a}$ and $7 \mathrm{~b}$ ) and when the tip potentials were $+0.60 \mathrm{~V}$ vs. $\mathrm{Ag} / \mathrm{AgCl} / \mathrm{KCl}$ reference electrode and $-0.70 \mathrm{Vvs} . \mathrm{Ag} / \mathrm{AgCl} / \mathrm{KCl}$ reference electrode respectively at different immersion time in natural seawater. 

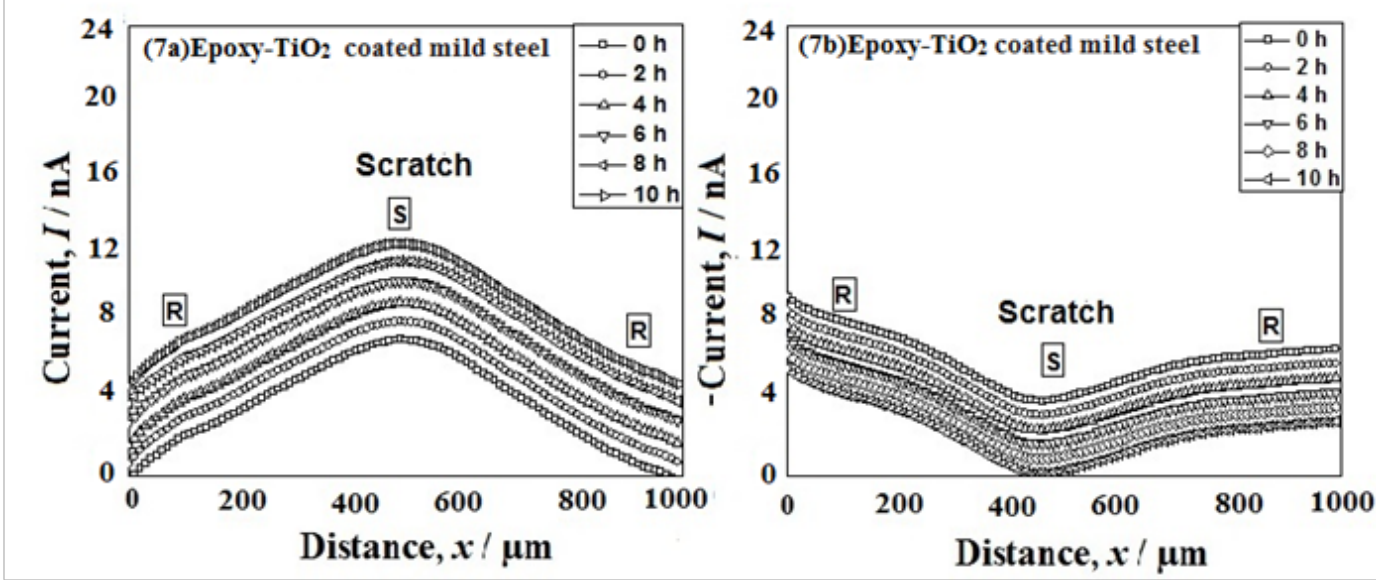

Figure $8 \mathrm{SECM}$ lines scan near the scratch of epoxy-TiO coated mild steel (Fig. $8 \mathrm{a}$ and $8 \mathrm{~b}$ ) and when the tip potentials were $+0.60 \mathrm{~V} \mathrm{vs.Ag/AgCl} / \mathrm{KCl}$ reference electrode and $-0.70 \mathrm{~V} v$ s. $\mathrm{Ag} / \mathrm{AgCl} / \mathrm{KCl}$ reference electrode respectively at different immersion time in natural seawater.

Steel and stainless steel are widely used in different industrial fields because of their mechanical and corrosion properties. However, they still tend to corrode in the presence of aggressive medium. The corrosion resistance behavior of different nanoparticle coatings or coating films deposited onto steel substrate has been extensively studied, ${ }^{22-26}$ as summarized in Table $3 . \mathrm{TiO}_{2}$ has excellent chemical stability, heat resistance and low electron conductivity, making it an excellent anti-corrosion material. But pure $\mathrm{TiO}_{2}$ film is mostly used in catalyst chemistry. Some $\mathrm{TiO}_{2}$ films have been reported as protective coatings on steel substrate. ${ }^{27}$

Table 3 Corrosion protective nanoparticle coatings on steel substrates.

\begin{tabular}{|c|c|c|c|c|}
\hline Composition/ Nanoparticle & Type of steel & Method of coating & Thickness $(\mu \mathrm{m})$ & References and year \\
\hline $\mathrm{ZnO}$ & phosphated steel panels & Dip-coating & $0.2-1.6$ & $22[2013]$ \\
\hline Organoclay-ZrO & Mild Steel & Dip-coating & $0.4-1.2$ & $23[2011]$ \\
\hline Silane-SiO ${ }_{2}$ & Mild Steel & Dip-coating & $0.3-1.4$ & $24[2009]$ \\
\hline $\mathrm{CaO}-\mathrm{P}_{2} \mathrm{O}_{5}$ & $316 \mathrm{LSS}$ & Spin-coating & $1.0-1.4$ & $25[2007]$ \\
\hline SiO2-PMMA & 304 SS & Dip-coating & $1.0-2.0$ & $26[2004]$ \\
\hline $\mathrm{ZrO}_{2}$ & Carbon steel & Dip-coating & $0.3-1.8$ & $27[2001]$ \\
\hline $\mathrm{Al}_{2} \mathrm{O}_{3}$ & $316 \mathrm{LSS}$ & Dip-coating & $2.0-3.0$ & $28[1999]$ \\
\hline
\end{tabular}

\section{Electrochemical impedance spectroscopy (EIS) measurements}

The Bode plots for epoxy coated mild steels without and with nano-titania particles in natural seawater are depicted in the Figure 9, Figure 10 respectively. It was possible to fit all the impedance spectra using the equivalent circuit model shown in Figure 11. The spectra for the two samples exhibit two time constants corresponding to the resistance and capacitance behavior of the coating film. It is evident from the Figure 9, Figure 10 that the EIS spectra of the scratched sample show two resistances. The resistance in the high frequency region is the resistance of the film $\left(R_{\mathrm{f}}\right)$ that explains the coating behavior. On the other hand, the resistance in the low frequency region is the charge transfer resistance $\left(R_{\mathrm{c}}\right)$ that corresponds to the corrosion reaction occurring on the steel. Moreover, the EIS spectrum suggests the presence of two capacitances. The capacitance at high frequency region corresponds to the film capacitance $\left(C_{f}\right)$, since it shows a lower value. On the other hand, the capacitance in the low frequency region is due to the double layer capacitance $\left(C_{\mathrm{dd}}\right)$, because it shows a higher value of $10^{-5} \sim 10^{-7} \mathrm{~F} \mathrm{~cm}^{-2}$. The high resistance and low capacitance values in the high frequency region can be attributed to the polymeric phase. The low resistance and high capacitance values in the low frequency region can be attributed to the corrosion reaction taking place at the substrate surface.

Figure 12 shows the charge transfer resistance $\left(R_{\mathrm{ct}}\right)$, film resistance $\left(R_{\mathrm{f}}\right)$ and double layer capacitance $\left(C_{\mathrm{dd}}\right)$ obtained by curve fitting using the equivalent circuit model shown in the figure. The epoxy$\mathrm{TiO}_{2}$ coated steel showed relatively higher resistance than the coated mild steel during the wet/dry cycles. A decrease in $R_{\mathrm{ct}}$ shows that the corrosion process takes place at the coated samples. A low $R_{\mathrm{ct}}$ value of $58 \mathrm{k} \Omega \mathrm{cm}^{2}$ is initially observed and decreased further to $15 \mathrm{k} \Omega \mathrm{cm}^{2}$ after 15 days in the case of the epoxy coated mild steel. On the other hand, a high $R_{\mathrm{ct}}$ value of $120 \mathrm{k} \Omega \mathrm{cm}^{2}$ is observed for epoxy coated mild steel with $\mathrm{TiO}_{2}$ nanoparticles and reaches a constant value of 69 $\mathrm{k} \Omega \mathrm{cm}^{2}$ after 9 days. In addition, the $R_{\mathrm{ct}}$ value of epoxy coated mild steel with $\mathrm{TiO}_{2}$ nanoparticles at 15 days is significantly higher $(65$ $\left.\mathrm{k} \Omega \mathrm{cm}^{2}\right)$ than that of epoxy coated mild steel $\left(16 \mathrm{k} \Omega \mathrm{cm}^{2}\right)$. The $R_{\mathrm{f}}$ value of the mild steel decreased from 9.2 to $1.7 \mathrm{k} \Omega \mathrm{cm}^{2}$ during the test time of 15 days. $R_{\mathrm{f}}$ value describes the ionic transport through the coating film. Thus, the decrease of $R_{\mathrm{f}}$ during the first few days of the test corresponds to the penetration of the solution through the 
coating. The decrease of $R_{\mathrm{f}}$ during the test time indicates a loss of the barrier properties of the film. However, $R_{\mathrm{f}}$ of the epoxy coated mild steel with $\mathrm{TiO}_{2}$ nanoparticles decreases more slowly during the 15 day period from 18.0 to $10.5 \mathrm{k} \Omega \mathrm{cm}^{2}$. Thus, $R_{\mathrm{f}}$ of epoxy coated mild steel with $\mathrm{TiO}_{2}$ nanoparticle shows a higher value than that of epoxy coated mild steel. The slow decrease in film resistance of epoxy- $\mathrm{TiO}_{2}$ coated sample is due to the formation of corrosion product of the oxides of Ti complexes which prevent the drastic decrease in film resistance of the sample. Apart from the film providing barrier protection, the formation of the oxides of Ti complexes on the surface also provides additional barrier protection extending the lifetime of the coating.

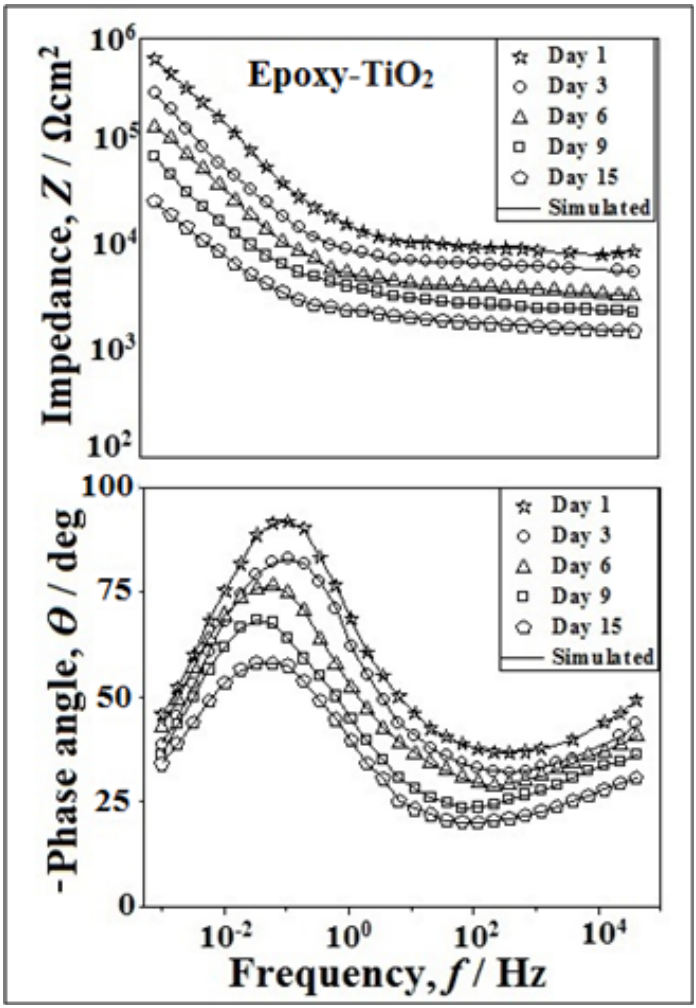

Figure 9 Bode plots of scratched epoxy coated mild steel after wet/dry cycles test in natural seawater for various days.

The $C_{\mathrm{d}}$ value of epoxy coated mild steel was low value in the order of $2.2 \times 10^{-7} \mathrm{~F} \mathrm{~cm}^{-2}$ initially and then these values increased gradually to $6.8 \times 10^{-6} \mathrm{~F} \mathrm{~cm}^{-2}$ with increase in immersion time. The $C_{\mathrm{dl}}$ values of epoxy- $\mathrm{TiO}_{2}$ coated mild steel showed a lower value of $1.5 \times 10^{-6}$ $\mathrm{F} \mathrm{cm}^{-2}$ at $15^{\text {th }}$ day. The value of $C_{\mathrm{dl}}$ depends on the corrosion area under the film. Thus, the lower value of $C_{\mathrm{dl}}$ of epoxy coated mild steel with $\mathrm{TiO}_{2}$ nanoparticles means a smaller area of corrosion under the film as compared with epoxy coated mild steel without nanoparticles. Thus, an increase of $R_{\mathrm{ct}}$ and decrease of $C_{\mathrm{dl}}$ occurred in the epoxy coated mild steel with $\mathrm{TiO}_{2}$ nanoparticles during the corrosion test The enhancement of corrosion resistance of epoxy coated mild steel with $\mathrm{TiO}_{2}$ nanoparticles is due to the formation of corrosion products containing $\mathrm{TiO}_{2}$ in the scratched surface of the mild steel.

Thus, the coating resistance decreased continuously with increasing the immersion time due to the diffusion and penetration of water and movement of ionic species through the coating film. ${ }^{28}$ This causes the coating conductivity to increase. The electrolyte diffuses in the coating film and arranges conducting paths at various depths through the coating film. ${ }^{29}$ This can be attributed to the increase in the rate of corrosion reactions, possibly through the presence of further pores in the coating or an increase in the area exposed at the base of the existing pores or flaws.

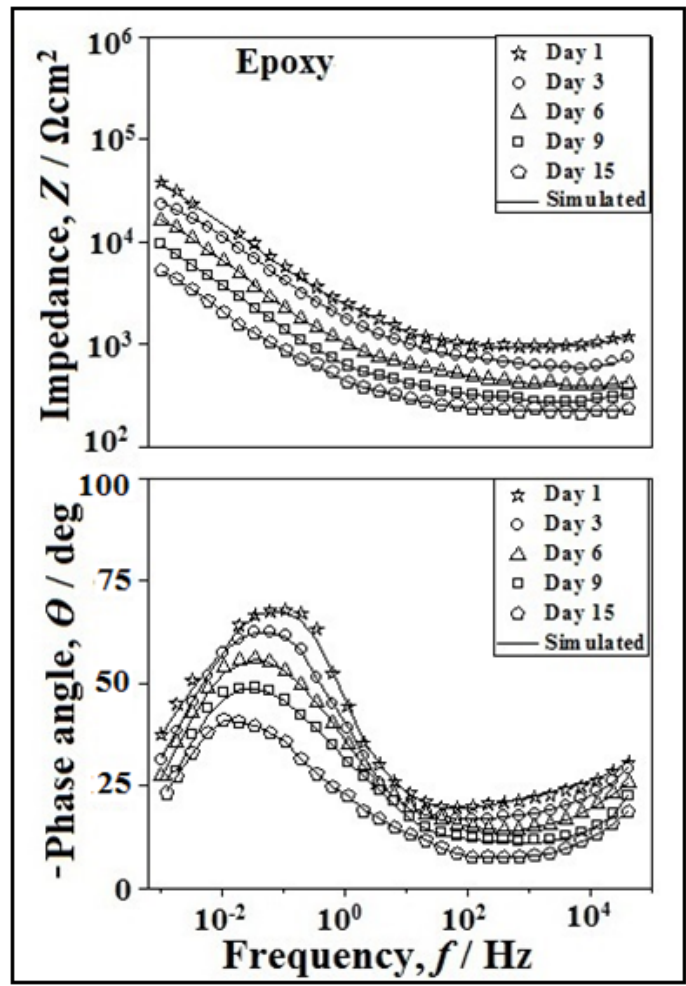

Figure 10 Bode plots of scratched epoxy-TiO, coated mild steel after wet/ dry cycles test in natural seawater for various days.

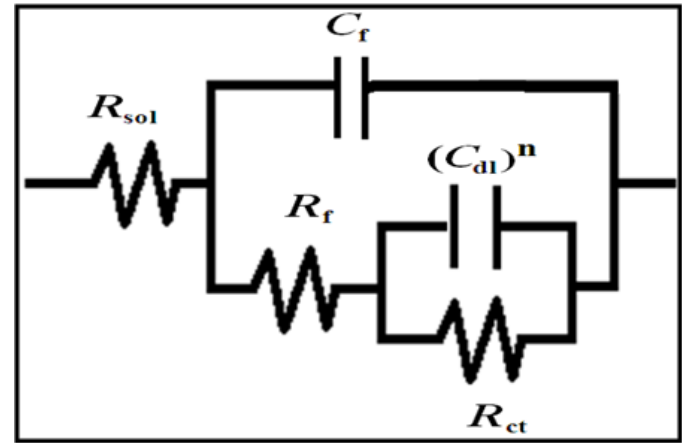

Figure II Equivalent circuit diagram for scratched epoxy coated and epoxy$\mathrm{TiO}_{2}$ coated mild steels after wet/dry corrosion test in natural seawater for various days.

\section{Surface characterization}

FE-SEM analysis: In order to identify the corrosion products of coated steel after 15 days of wet/dry cyclic corrosion test, the SEM analysis was carried out. The cross section of SEM image and EDX results for epoxy- $\mathrm{TiO}_{2}$ coated carbon steel are shown in Figure 13. EDX analysis confirmed the presence of $\mathrm{TiO}_{2}$ in the inner rust of carbon steel. This is due to the formation of complex iron oxides containing $\mathrm{TiO}_{2}$ during the corrosion test. This result implies that complex oxides are formed during the cyclic corrosion test, which enhances the barrier protection properties of the epoxy coated steel.

TEM analysis: TEM observation was performed to investigate the nanostructure of the rust as shown in Figure 14. The inner rust was cut 
by FIB and then examined by TEM. Other elements except iron was shown as a little white color in the bright field image of the TEM. Thus, it was possible to select the rust containing $\mathrm{TiO}_{2}$ by EDX analysis. The spot position of the micrograph analysis is shown in Figure 14a, Figure $14 \mathrm{~b}$ shows the elemental composition of $\mathrm{TiO}_{2}$ and $\mathrm{O}$ in mass $\%$ corresponding to each spot in Figure 14a. This figure clearly shows an enrichment of $\mathrm{TiO}_{2}$ from spot 1 6 and also a decrease of $\mathrm{Fe}$. Actually, these layers are said to be made by the oxide containing Ti that could increase the corrosion resistance of epoxy- $\mathrm{TiO}_{2}$ coated steel.

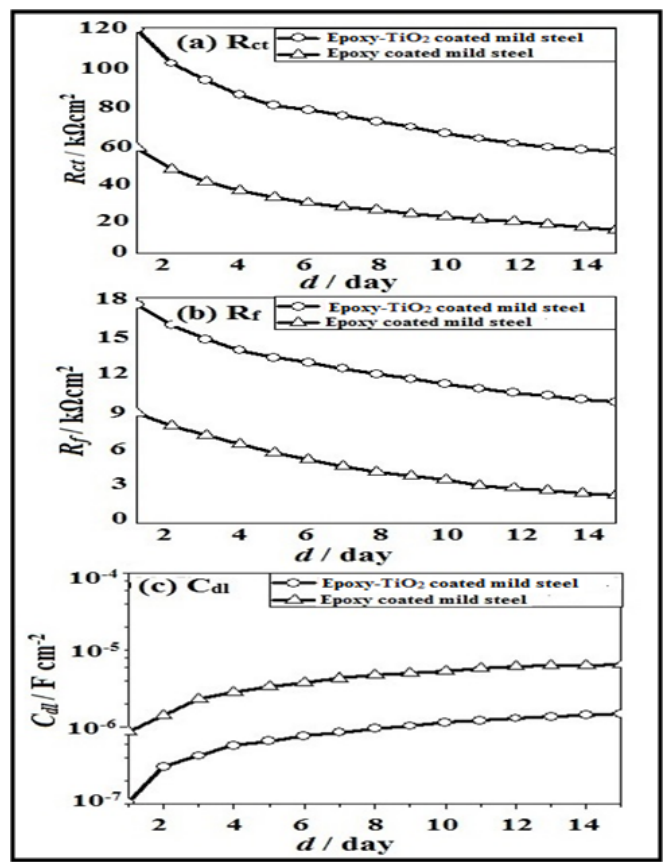

Figure 12 Impedance values of $R_{\mathrm{cc}}, \mathrm{Rf}$ and $C_{\mathrm{d}}$ for scratched epoxy coated and epoxy- $-\mathrm{TiO}_{2}$ coated mild steels after wet/dry cycles test in natural seawater.

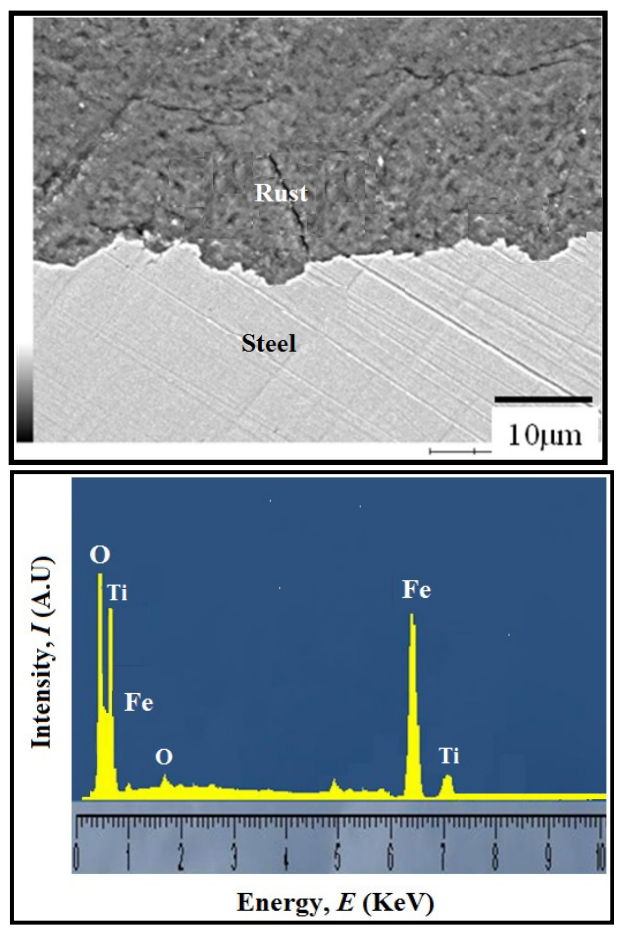

Figure 13 SEM image and EDX mapping of the rust formed on the epoxy$\mathrm{TiO}_{2}$ coated mild steel after wet and dry cyclic corrosion test.
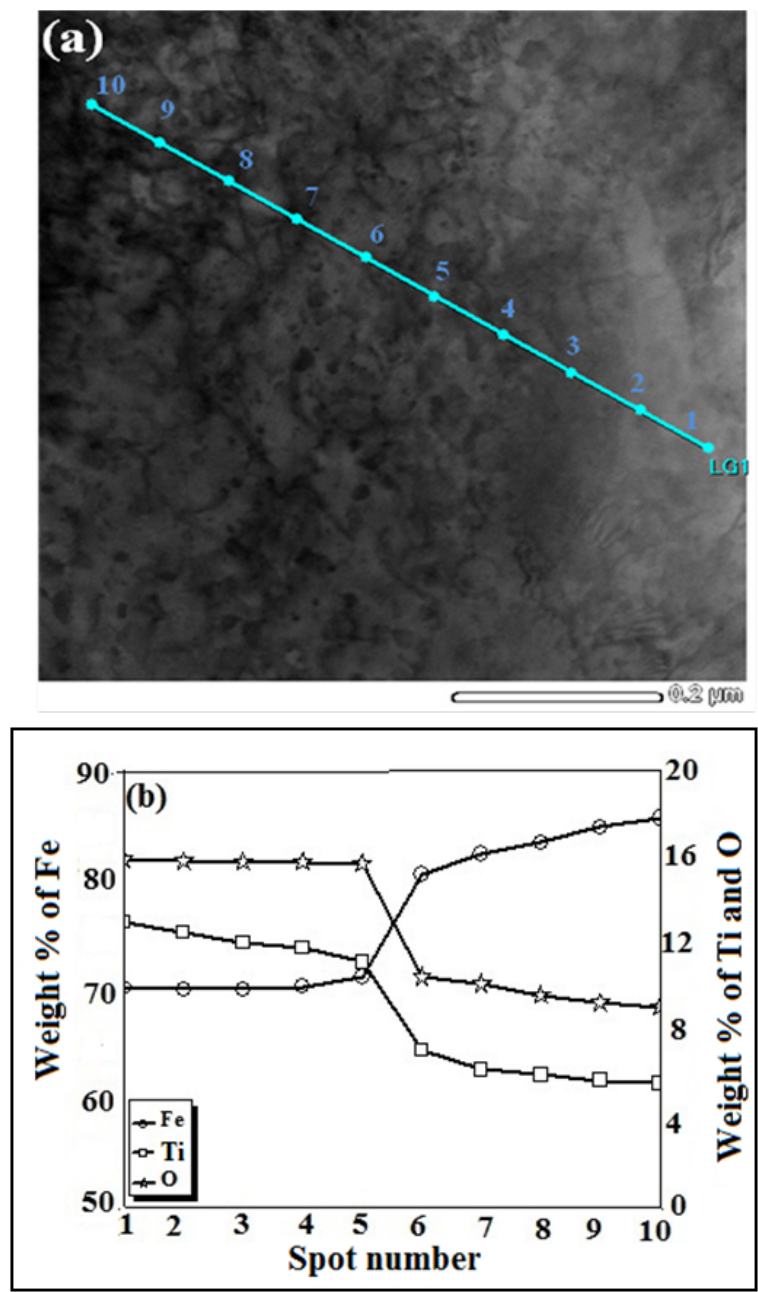

Figure 14 (a) Bright field image and (b) Line profile of EDX according to the spots in Figure 14a for the epoxy- $\mathrm{TiO}_{2}$ coated mild steel in natural seawater (after wet/dry cycles test).A small portion of the rust was cut by FIB from the SEM rust part and was analyzed by TEM.

\section{Corrosion inhibition mechanism of the $\mathrm{TiO}_{2}$ nanoparticles}

It has been shown that the epoxy coating on metal showed enhanced anticorrosion properties. However, the improvement was most pronounced in the case of surface when $\mathrm{TiO}_{2}$ nanoparticles were added to the epoxy coating. The $\mathrm{TiO}_{2}$ nanoparticles could enhance the corrosion protection properties of the coating through two main mechanisms. Both barrier and active protection mechanisms are expected using this nanoparticle. The $\mathrm{TiO}_{2}$ nanoparticles are slightly soluble in water releasing inhibitive species such as $\mathrm{Ti}^{4+}$ cations. The $\mathrm{Ti}^{4+}$ cations released reaches to the coating/metal interface and react with hydroxyl ions produced on the cathodic regions. As a result, a protection layer is precipitated on the cathodic regions causing cathodic sites blockage against corrosive species access. This results in less under film corrosion and coating delamination. The second mechanism is the high barrier protection properties of the nanoparticles. The nanoparticles produce high barrier protection properties due to their smaller size and greater surface area. Thus, the addition of $\mathrm{TiO}_{2}$ to epoxy coating increases specific surface area and inhibits corrosion. Moreover, the addition of $\mathrm{TiO}_{2}$ nanoparticles to the epoxy coating produces strong bonds with the coating matrix. Therefore, the coating damage is not significant as a result 
of electrolyte diffusion into the coating matrix. It can be seen that as the nanoparticles were added to the epoxy coating, the corrosion protection properties of the nanoparticles increased.

In EIS, epoxy- $\mathrm{TiO}_{2}$ coated steel which contains $\mathrm{TiO}_{2}$ in the epoxy shows increased value of $R_{\mathrm{ct}}$ and $R_{\mathrm{f}}$ after the wet/dry corrosion test. The presence of $\mathrm{TiO}_{2}$ in epoxy coat on steel surfaces increases $R$ of the steel substrate itself because the anodic reaction is suppressed by this element. Actually, $R$ of opoxy-TiO coated steel displayed a much higher value of $120 \mathrm{k} \Omega \mathrm{cm}^{2}$ as compared with that of epoxy coated mild steel of $58 \mathrm{k} \Omega \mathrm{cm}^{2}$ at 1 day of the wet/dry corrosion test. Moreover, the formation of the complex oxide layer containing $\mathrm{TiO}_{2}$ suppresses the anodic reaction. The anodic current is suppressed significantly by the formation of this oxide layer. In the actual results, $R_{\mathrm{ct}}$ of epoxy- $\mathrm{TiO}_{2}$ coated steel was higher at $65 \mathrm{k} \Omega \mathrm{cm}^{2}$ as compared with the epoxy coated mild steel of $15 \mathrm{k} \Omega \mathrm{cm}^{2}$ after 15 days of the wet/dry test. Thus, the effect of epoxy- $\mathrm{TiO}_{2}$ coated on the steel is also considered significant by forming corrosion products at defects and scratches in the film, which suppress the anodic reaction. In the case of $R_{\mathrm{f}}$, the $R_{\mathrm{f}}$ of epoxy-TiO ${ }_{2}$ coated mild steel shows a slightly higher value as compared with coated mild steel. The film of epoxy$\mathrm{TiO}_{2}$ coated steel has little damage because the rust is much smaller. Thus, $R_{\mathrm{f}}$ of epoxy- $\mathrm{TiO}_{2}$ coated steel shows a higher value. The $C_{\mathrm{dl}}$ of epoxy- $\mathrm{TiO}_{2}$ coated mild steel shows a lower value as compared with coated mild steel. Since the value of $C_{\mathrm{dl}}$ depends on the corrosion area under the thin film, the lower value of $C_{\mathrm{d} 1}$ of epoxy- $\mathrm{TiO}_{2}$ coated on steel indicates a smaller area of corrosion under the film as compared with epoxy coated mild steel. These analyzes demonstrated that the presence of $\mathrm{TiO}_{2}$ nanoparticles in the epoxy on the steel had a beneficial effect on corrosion resistance of coated steel by forming corrosion products in wet/dry cyclic test.

\section{Conclusion}

The effect of introducing nano-titania to the epoxy coating on mild steel has been investigated using SECM and EIS techniques. It has been concluded from the line profile and topography analysis of SECM technique, the dissolved oxygen and iron dissolution tip current decreases implying that the $\mathrm{TiO}_{2}$ nanoparticles plays a role in protecting the metal surface. The dissolution of $\mathrm{Fe}^{2+}$ in nano-titania on epoxy coated steel was lower than that in epoxy coated mild steel, resulting in a lower anodic current of steel. It has been shown from EIS studies, the increase in film resistance and the charge transfer resistance implies that the nano-titania and the complex oxide formation provide barrier protection to the coating as shown from the EIS studies. In other words, the high resistance of anodic dissolution of $\mathrm{Fe}$ in nano-titania coated on steel showed that the dissolution at the scratch was deeply suppressed in the epoxy coated steel with nanoparticle. Therefore, $\mathrm{TiO}_{2}$ nanoparticles enhanced the barrier protection performance of the epoxy coating compared to other nanoparticles in the organic coating on steels. Thus, titania nanoparticles can be introduced into the epoxy coatings for the corrosion protection of mild steel.

\section{Acknowledgements}

None.

\section{Conflict of interest}

The author declares no conflict of interest.

\section{References}

1. Linda Garverick. Corrosion in the Petrochemical Industry. USA: ASM International; 1994.
2. E Bardel. Corrosion and Protection. London, UK, 2003.

3. ES Ferreira C, Giacomelli FC, Giacomelli A, et al. Evaluation of the inhibitor effect of L-ascorbic acid on the corrosion of mild steel. Mater Chem Phys. 2004;83(1):129-134.

4. MM Popovic, BN Grgur, VB Miskovic Stankovic, et al. Corrosion studies on electrochemically deposited PANI and PANI/epoxy coatings on mild steel in acid sulfate solution. Prog Org. Coat. 2005;52(4):359-365.

5. H Leidheiser. Corrosion of painted metals-a review. Corrosion 1982;38:374-383.

6. Y González García, S González, RM Souto. Electrochemical and structural properties of a polyurethane coating on steel substrates for corrosion protection. Corros Sci. 2007;49:3514-3526.

7. GW Walter. A critical review of the protection of metals by paints. Corros Sci. 1986. 26(1):27-38

8. EPM Van Westing, GM Ferrari, JHW de Wit. The determination of coating performance with impedance measurements:I. Coating polymer properties. Corros Sci. 1993;34(9):1511-1530.

9. AJ Vreugdenhil, VJ Gelling, ME Woods, et al. The role of cross linkers in epoxy-amine crosslinked silicon sol-gel barrier protection coatings. Thin Solid Films. 2008;517(2):538-543

10. Min Qian, Andrew Mcintosh Soutar, Xiu Hui Tan, et al. Two-part epoxysiloxane hybrid corrosion protection coatings for carbon steel. Thin Solid Films. 2009;517(17):5237-5242.

11. M Rashvand, Z Ranjbar. Effect of nano- $\mathrm{ZnO}$ particles on the corrosion resistance of polyurethane-based waterborne coatings immersed in sodium chloride solution via EIS technique. Prog Org Coat. 2013;76(10):1413-1417.

12. DJ Mills, SS Jamali, K Paprocka. Investigation into the Effect of Nanosilica on the Protective Properties of Polyurethane Coatings. Surf Coat Technol. 2012;209:137-142.

13. Gonzlez Garc Y, Gonzalez S, Souto RM. Electrochemical and Structural Properties of a Polyurethane Coating on Steel Substrates for Corrosion Protection. Corros Sci. 2007;49(9):3514-3526.

14. Dolatzadeh F, Moradian S, Mehdi Jalili M. Influence of Various Surface Treated Silica Nanoparticles on the Electrochemical Properties of $\mathrm{SiO}_{2} /$ Polyurethane Nanocoatings. Corros Sci. 2011;53(12):4248-4257.

15. S Zhou, L Wu, J Sun, et al. The change of the properties of acrylic-based polyurethane via addition of nano-silica. Prog Org Coat. 2002;45(1):3342.

16. RM Souto, Y Gonzalez Garcia, S Gonzalez, et al. Damage to paint coatings caused by electrolyte immersion as observed in situ by scanning electrochemical microscopy. Corros Sci. 2004;46(11):2621-2628.

17. RM Souto, Y González García, J Izquierdo, et al. Examination of organic coatings on metallic substrates by scanning electrochemical microscopy in feedback mode: Revealing the early stages of coating breakdown in corrosive environments. Corros Sci. 2010;52:748-753.

18. R Akid, DJ Mills. A comparison between conventional macroscopic and novel microscopic scanning electrochemical methods to evaluate galvanic corrosion. Corros Sci. 2001;43(7):1203-1216.

19. X Joseph Raj, T Nishimura. Studies on galvanic corrosion of ironmagnesium couple by scanning electrochemical microscopy in $0.1 \mathrm{M}$ $\mathrm{NaCl}$ solution. J Ind Eng Chem. 2016;41:141-150.

20. X Joseph Raj, T Nishimura. Scanning Electrochemical Microscopy for the Investigation of Galvanic Corrosion of Iron with Zinc in $0.1 \mathrm{M} \mathrm{NaCl}$ Solution. J Mat Eng Perform. 2016;25(2):474-486.

21. SM Mirabedini, M Behzadnasab, K Kabiri. Effect of various combinations of zirconia and organoclay nanoparticles on mechanical and thermal properties of an epoxy nanocomposite coating. Composites: Part A. 2012;43(11):2095-2106. 
22. Alka Phanasgaonkar, VS Raja. Influence of curing temperature, silica nanoparticles- and cerium on surface morphology and corrosion behaviour of hybrid silane coatings on mild steel. Surf Coat Technol. 2009;203:2260-2271.

23. U Vijayalakshmi, S Rajeswari. Synthesis and characterization of sol-gel derived glass-ceramic and its corrosion protection on $316 \mathrm{~L} \mathrm{SS}$. $J$ SolGel Sci Technol. 2007;43(2):251-258.

24. S Ono, H Tsuge, Y Nishi, et al. Improvement of Corrosion Resistance of Metals by an Environmentally Friendly Silica Coating Method. $J$ SolGel Sci Technol. 2004;29(3):147-153.

25. L Fedrizzi, FJ Rodriguez, S Rossi, et al. The use of electrochemical techniques to study the corrosion behaviour of organic coatings on steel pretreated with sol-gel zirconia films. Electrochim Acta. 2001;46:37153724.
26. J Masalski, J Gluszek, J Zabrzeski, et al. Improvement in corrosion resistance of the $316 \mathrm{~L}$ stainless steel by means of $\mathrm{Al}_{2} \mathrm{O}_{3}$ coatings deposited by the sol-gel method. Thin Solid Films. 1999;349(1-2):186-190.

27. A Nazeri, PP Trzaskoma, D Bauer. Synthesis and Properties of Cerium and Titanium Oxide Thin Coatings for Corrosion Protection of 304 Stainless Steel. J Sol Gel Sci Technol. 1997;10(3):317-331.

28. M Niknahad, S Moradian, S Mirabedini. The adhesion properties and corrosion performance of differently pretreated epoxy coatings on an aluminum alloy. Corros Sci. 2010;52(6):1948-1957.

29. D Brasher, A Kingsbury. Electrical measurements in the study of immersed paint coatings on metal. I. Comparison between capacitance and gravimetric methods of estimating water-uptake. J Appl Chem. 1954;4(2):62-72. 